\title{
Evolution of Microstructures and Mechanical Properties of Zr-Containing Y-CLAM During Thermal Aging
}

\author{
Dongping Zhan ${ }^{1} \cdot$ Guoxing Qiu ${ }^{2,3} \cdot$ Changsheng $\mathrm{Li}^{2} \cdot$ Yongkun Yang ${ }^{1} \cdot$ Zhouhua Jiang $^{1} \cdot$ Huishu Zhang ${ }^{4}$
}

Received: 27 August 2019 / Revised: 23 October 2019 / Published online: 5 February 2020

(c) The Chinese Society for Metals (CSM) and Springer-Verlag GmbH Germany, part of Springer Nature 2020

\begin{abstract}
The thermal stability and mechanical properties of China low activation martensitic steel with $\mathrm{Zr}$ and $\mathrm{Y}$ were investigated via thermal aging at $550{ }^{\circ} \mathrm{C}$ for $8000 \mathrm{~h}$. The Laves phase content monotonically increased with thermal aging, and the volume fraction of the Laves phases stabilized in the alloy after $3000 \mathrm{~h}$ of thermal aging. The observed degradation in mechanical properties was because of the coarsening of $M_{23} \mathrm{C}_{6}$ carbides and matrix grains during the earlier stages of thermal aging. The precipitation of Laves phases and $\mathrm{V}_{3} \mathrm{Zr}_{3} \mathrm{C}$ particles increased the strength and hardness of the alloy. Grain coarsening was the primary reason for the decrease in impact properties, and the ductile-to-brittle transition temperature increased from -71 to $-48{ }^{\circ} \mathrm{C}$ after $8000 \mathrm{~h}$ of thermal aging.
\end{abstract}

Keywords Thermal stability $\cdot$ Zr-containing RAFM $\cdot$ Precipitation $\cdot$ Microstructures $\cdot$ Mechanical properties

\section{Introduction}

Reduced-activation ferritic/martensitic (RAFM) steels have been considered as the primary candidate structural materials for advanced fusion reactors because of their excellent microstructure stability, high-temperature mechanical properties, and irradiation resistance [1]. In the beginning, RAFM steels were modified from heat-resistant $9 \mathrm{Cr}-1 \mathrm{Mo}-\mathrm{Nb}$ steels for thermal power plants by the substitution of Mo and $\mathrm{Nb}$, high activation alloying elements, with $\mathrm{W}$ and $\mathrm{Ta}$, low activation alloying elements, respectively [2]. Several countries have developed their own RAFM steels: for instance [3], Eurofer 97 (Europe), F82H (Japan), 9Cr-2WVTa (USA), CLF-1 (China), and CLAM (China).

Available online at https://link.springer.com/journal/40195.

Guoxing Qiu

guoxingqiu2008@126.com

1 School of Metallurgy, Northeastern University, Shenyang 110819, China

2 State Key Laboratory of Rolling and Automation, Northeastern University, Shenyang 110819, China

3 School of Metallurgical Engineering, Xi' an University of Architecture and Technology, Xi' an 710055, China

4 School of Metallurgy Engineering, Liaoning Institute of Science and Technology, Benxi 117004, China
To ensure the low activity of alloys, only a limited number of elements can be added to the RAFM steel to improve its mechanical properties. Currently, the main research is focused on $\mathrm{Y}, \mathrm{Ti}$, and $\mathrm{Zr}$ element. The authors have systematically studied the effects of $Y$ on inclusions, structure, and properties of CLAM steel and developed a Y-containing CLAM steel (Y-CLAM) [4]. It is indicated that Y acts as deoxidizers, desulfurizers, and modifiers. The CLAM steel modified by $0.01 \mathrm{wt} . \%-0.05 \mathrm{wt} . \% \mathrm{Y}$ can have better properties than other RAFM steels. In addition, yttria or yttrium oxide is commonly introduced to oxide dispersion strengthened (ODS) steels, which are widely studied worldwide [5].

Darling et al. [6] have reported that the ODS alloys with $\mathrm{Zr}$ still have the ability to resist grain growth at $1373{ }^{\circ} \mathrm{C}$. Xu et al. [7] have reported that an addition of $\mathrm{Zr}$ leads to the finer grain size of the $9 \mathrm{Cr}-\mathrm{Zr}-\mathrm{ODS}$ alloy, which was only $0.8 \mu \mathrm{m}$. $\mathrm{Zr}$ can also be used to refine Y-containing oxide particles in 9Cr-ODS alloys prepared via mechanical alloying, which are other candidate structural materials for fusion reactors. Currently, $\mathrm{Zr}$ is usually used for grain refinement and strengthening in RAFM steel alloys [8, 9]. Since 2011, Korea has developed a Zr-containing advanced reduced activation alloy (ARAA) for fusion reactors [8]. ARAA alloy exhibits a significantly longer creep-rupture time than Eurofer 97 steel, suggesting a positive influence of $\mathrm{Zr}$ addition. Chun et al. [10] reported that the improvement in impact and creep resistance by the addition of small amounts of $\mathrm{Zr}$ is attributed to the solution softening the 
effect of $\mathrm{Zr}$, which is associated with a reduced temperaturedependence of the yield strength. The authors have investigated the effects of $\mathrm{Zr}$ on the inclusions and mechanical properties of the Y-CLAM steel [11-13]. The compound addition of $\mathrm{Zr}$ and $Y$ can effectively improve the purity of the steel, refine the grain size, and improve the mechanical properties of steel. As a structural material for nuclear reactors, it is necessary to assess the thermal stability of Y-CLAM steel with $\mathrm{Zr}$ to ensure the structural integrity at prolonged exposure temperatures. The microstructure evolution of Eurofer 97, F82H, and CLAM after thermal aging had been described as precipitation of Laves phase, coarsening of grains and carbides, causing degradation in material strength and toughness [14]. However, few studies were conducted on the aging effects of Y-CLAM steel with $\mathrm{Zr}$ at $550{ }^{\circ} \mathrm{C}$. The aim of this study was to investigate the evolution of the microstructures and mechanical properties of $\mathrm{Zr}$ containing Y-CLAM steel that has been aged at $550{ }^{\circ} \mathrm{C}$ (the upper limit operating temperature) for up to $8000 \mathrm{~h}$.

\section{Materials and Experiments}

\subsection{Materials}

The alloy used in this study was prepared by the vacuum induction melting method, and its chemical composition is given in Table 1 . The ingot was first hot-forged into a $35 \mathrm{~mm} \times 50 \mathrm{~mm}$ plate and then hot-rolled into a 12 -mm-thick plate at temperatures between 950 and $1100{ }^{\circ} \mathrm{C}$. The plate was normalized at $1050{ }^{\circ} \mathrm{C}$ for $0.5 \mathrm{~h}$ and then tempered at $750{ }^{\circ} \mathrm{C}$ for $1.5 \mathrm{~h}$. All the samples were air-cooled. The tempered specimens were aged at $550{ }^{\circ} \mathrm{C}$ for $1000,1500,3000,5000$, and $8000 \mathrm{~h}$ in an air atmosphere to study their microstructural stability and mechanical properties.

\subsection{Measurement of Particle Size and Number}

The most common second phases in RAFM steel are $M_{23} \mathrm{C}_{6}(M=\mathrm{Cr}, \mathrm{Fe}), M X$, Laves phases (Fe, $\left.\mathrm{Cr}, \mathrm{W}\right)$, and the $\mathrm{Z}$ phase (Cr, V, N) [14]. Backscattered electron (BSE) imaging was conducted to clearly identify the particles in the samples because different types of particles show different Z-contrasts in the matrix [15]. Hald [16] reported that the $\mathrm{Z}$ phase $(\mathrm{Cr}, \mathrm{V}, \mathrm{N})$ can only be found in $9 \mathrm{Cr}$ steel after 30,000-40,000 $\mathrm{h}$ of thermal aging at $650{ }^{\circ} \mathrm{C}$. The fine $M X$ particles $(<40 \mathrm{~nm})$ cannot be detected in scanning electron microscope (SEM) images at low magnification because of the resolution limit of the SEM. Unlike the $M_{23} \mathrm{C}_{6}$ precipitates, the $\mathrm{W}$-rich Laves phase precipitates are visible as bright precipitates in a dark matrix, such that the Laves phases can be clearly distinguished in the BSE images at $2500 \times$ magnification. The particles were counted using 15-20 BSE images from each sample. The mean spatial particle diameter $\left(\bar{d}_{\mathrm{V}}\right)$ can be expressed as [17]

$\bar{d}_{\mathrm{V}}=\pi \cdot n / 2 \sum_{i=1}^{n}\left(1 / d_{\mathrm{Ai}}\right)$

where $n$ is the total number of particles in the observed area and $d_{\mathrm{Ai}}$ is the equivalent diameter, which is estimated as the diameter of a circle with the same area of a sectioned inclusion phase.

The number of particles per unit volume $\left(N_{\mathrm{V}}\right)$ was evaluated from the following relationship [17]:

$N_{\mathrm{V}}=N_{\mathrm{A}} / \bar{d}_{\mathrm{V}}$.

The volume fraction of the particle sections $\left(f_{\mathrm{V}}\right)$ can be expressed as [17]

$f_{\mathrm{V}}=\sum_{i=1}^{n}\left(\pi \cdot d_{\mathrm{Ai}}^{2} / 4\right) / A_{\mathrm{obs}}$

where $A_{\text {obs }}$ is the total observed area.

\subsection{Experiment}

Optical microscopy (OM), SEM, transmission electron microscopy (TEM), impact test, and tensile test samples were spark machined from the aging plates along the rolling direction. Villella's reagent $(1 \mathrm{~g}$ muriatic acid, $5 \mathrm{~mL}$ picric acid, and $100 \mathrm{~mL}$ alcohol) was used to etch the $\mathrm{OM}$ and SEM samples. The TEM samples were twin-jet polished using an electrolyte solution (95\% acetic acid and $5 \%$ perchloric acid) at $25{ }^{\circ} \mathrm{C}$. Bar samples $(25 \mathrm{~mm}$ length, $5.0 \mathrm{~mm}$ diameter) were used for the tensile tests at room temperature. Dog-bone-shaped flat specimens $(6.0 \mathrm{~mm} \times 2.0 \mathrm{~mm} \times 30 \mathrm{~mm})$ were used for the tensile tests at $600{ }^{\circ} \mathrm{C}$. The impact tests were conducted using full-size $\mathrm{V}$-notch Charpy specimens in the range of $-140{ }^{\circ} \mathrm{C}$ to $25{ }^{\circ} \mathrm{C}$, with the Charpy impact transition curves determined by fitting the Boltzmann function to the impact test data, to obtain the ductile-brittle transition temperature (DBTT). The hardness of the samples was measured with an FV-800 hardness tester.
Table 1 Chemical composition of the steel (wt.\%)

\begin{tabular}{lllllllllllll}
\hline $\mathrm{C}$ & $\mathrm{Si}$ & $\mathrm{Mn}$ & $\mathrm{Cr}$ & $\mathrm{W}$ & $\mathrm{V}$ & $\mathrm{Ta}$ & $\mathrm{Y}$ & $\mathrm{S}$ & $\mathrm{P}$ & $\mathrm{N}$ & $\mathrm{O}$ & $\mathrm{Zr}$ \\
\hline 0.11 & 0.05 & 0.45 & 9.2 & 1.50 & 0.22 & 0.15 & 0.043 & 0.005 & 0.0078 & 0.0157 & 0.0070 & 0.013 \\
\hline
\end{tabular}




\section{Results and Discussion}

\subsection{Microstructure}

OM micrographs of the thermally aged alloys are shown in Fig. 1, with typical martensitic structures observed in the samples. There was an obvious trend in grain growth, as shown in Fig. 2, where the average grain size increased during the thermal aging process and began to stabilize at the longest aging times. The grain size of the alloys increased from 11.2 to $14.2 \mu \mathrm{m}$ after $8000 \mathrm{~h}$ of thermal aging, which was $\sim 26.8 \%$ higher than that of the asreceived sample. This grain coarsening is a spontaneous process, where the surface energy is the driving force for the migration of grain boundaries [18]. Therefore, grain coarsening is an obvious characteristic of microstructure evolution during the thermal aging process, which affects the mechanical properties of the alloy [14].

Details of the alloy microstructures are shown in Fig. 3. Typical martensitic laths were observed in the thermally aged alloy. The microstructures underwent minimal changes, with the exception of lath coarsening during the thermal aging process. The width of the as-received lath martensite sample was $0.29 \mu \mathrm{m}$ (Fig. 3a), which increased by $45 \%$ after $1500 \mathrm{~h}$ of aging $(0.42 \mu \mathrm{m})$ (Fig. $3 \mathrm{~b})$. The martensite lath migrated and merged during the thermal aging process, with the width of the lath doubling to $0.58 \mu \mathrm{m}$ after $8000 \mathrm{~h}$ of thermal aging. Furthermore,

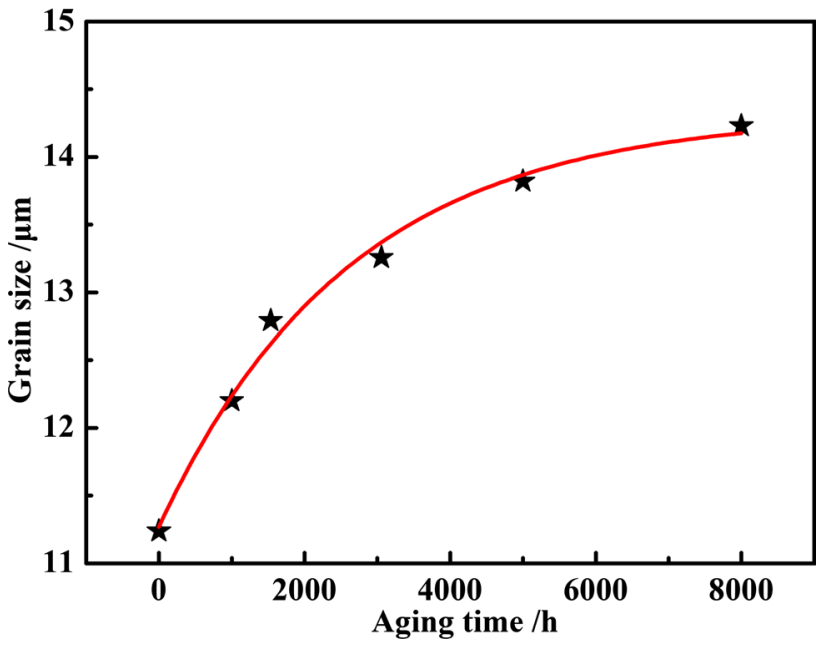

Fig. 2 Grain size evolution

subgrains were observed in the sample that was thermally aged for $8000 \mathrm{~h}$.

The misorientation angle distribution in the samples is shown in Fig. 4. The thermal aging time had a significant effect on angle distribution, particularly at the lowangle grain boundary (LAB: $4^{\circ}-10^{\circ}$ ) and the high-angle grain boundary ( $\left.\mathrm{HAB}: 50^{\circ}-60^{\circ}\right)$. The same result was also reported by Wang et al. [19] and Li et al. [20]. The LAB proportion gradually increased, whereas the HAB proportion decreased during the thermal aging process [21]. The
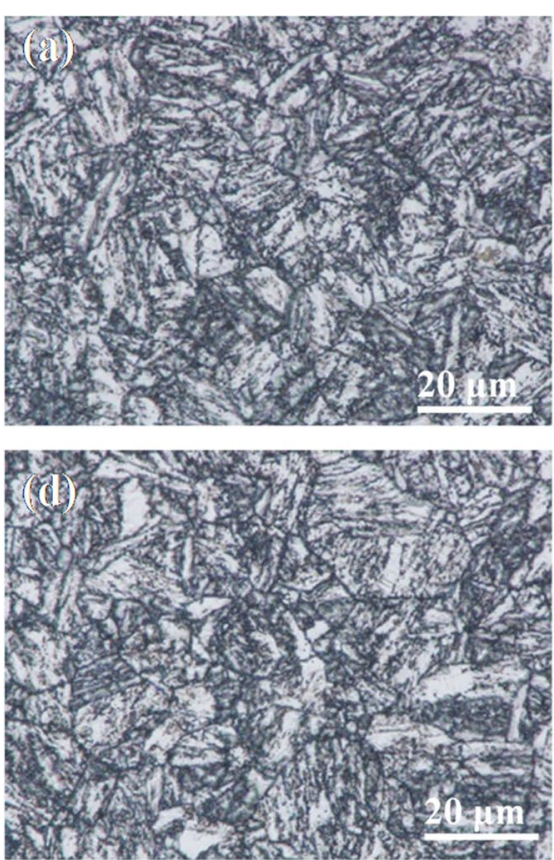
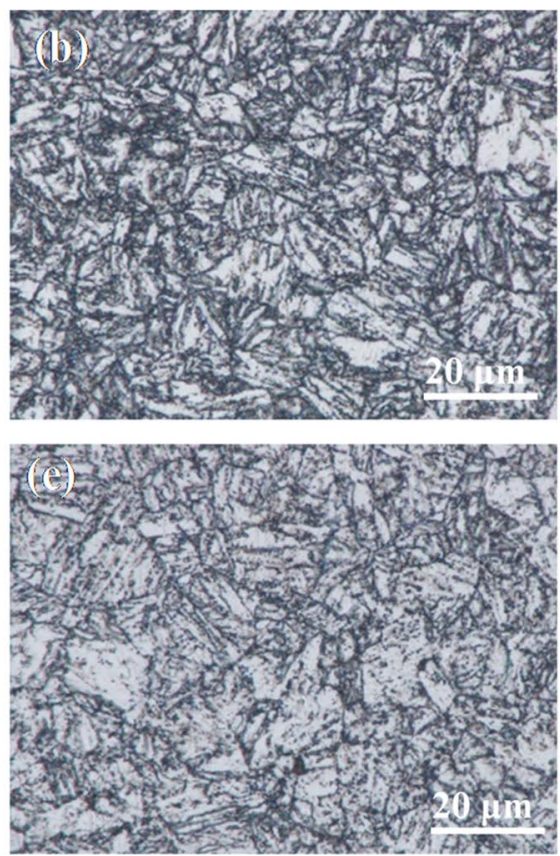
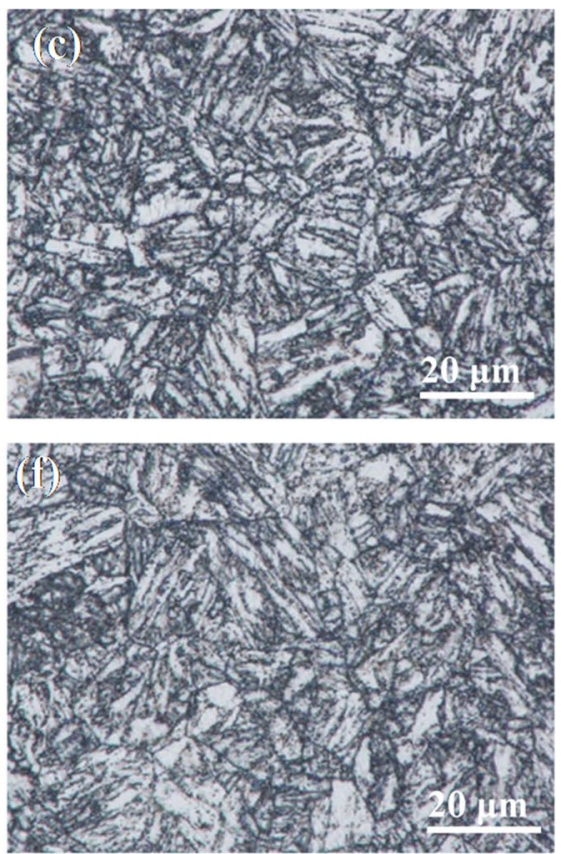

Fig. 1 Microstructure images of the as-received and aged samples: a as-received, b $1000 \mathrm{~h}, \mathbf{c} 1500 \mathrm{~h}, \mathbf{d} 3000 \mathrm{~h}, \mathbf{e} 5000 \mathrm{~h}$, and f $8000 \mathrm{~h}$ 

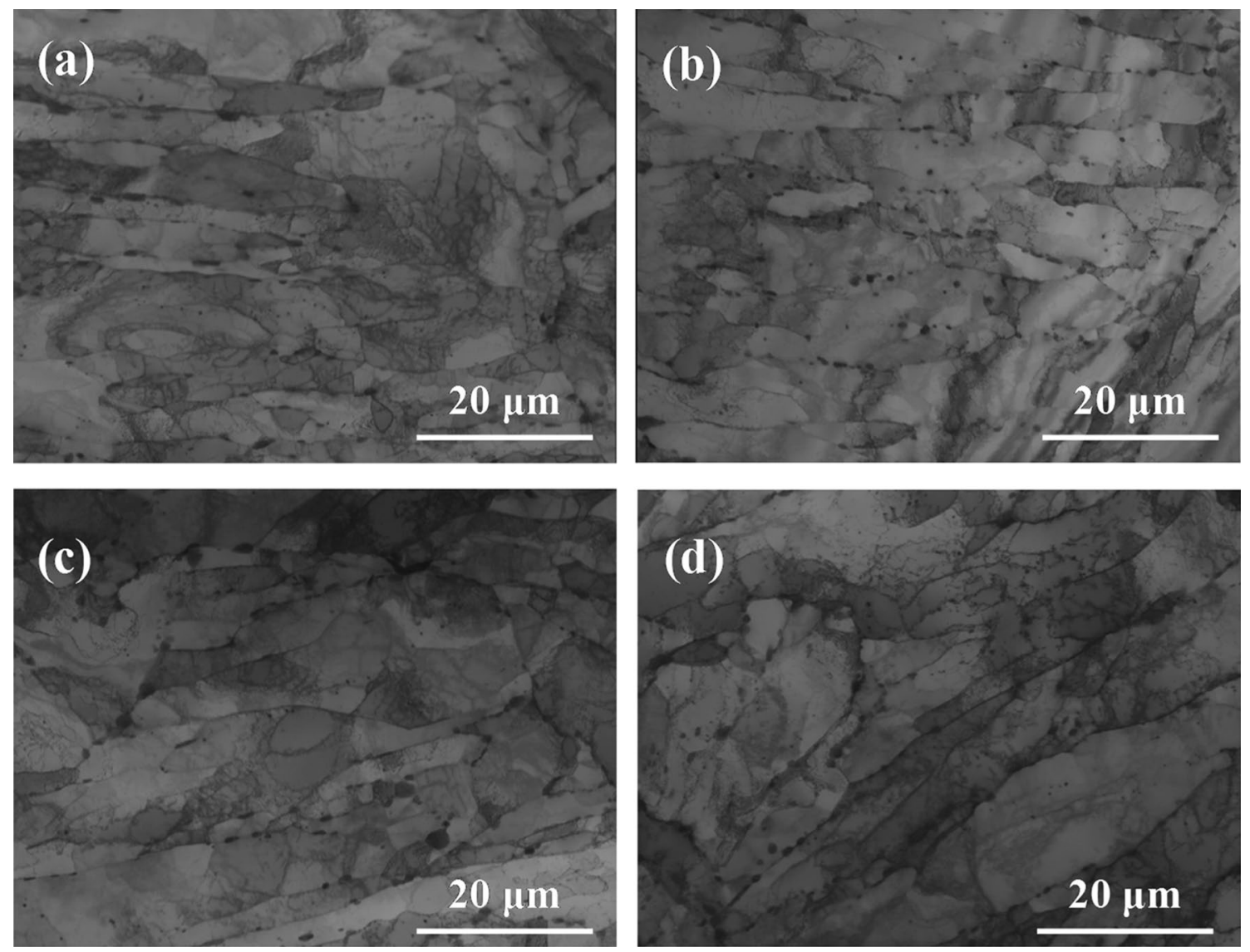

Fig. 3 TEM images of the as-received and aged samples: a as-received, b $1500 \mathrm{~h}, \mathbf{c} 5000 \mathrm{~h}$, and $\mathbf{d} 8000 \mathrm{~h}$

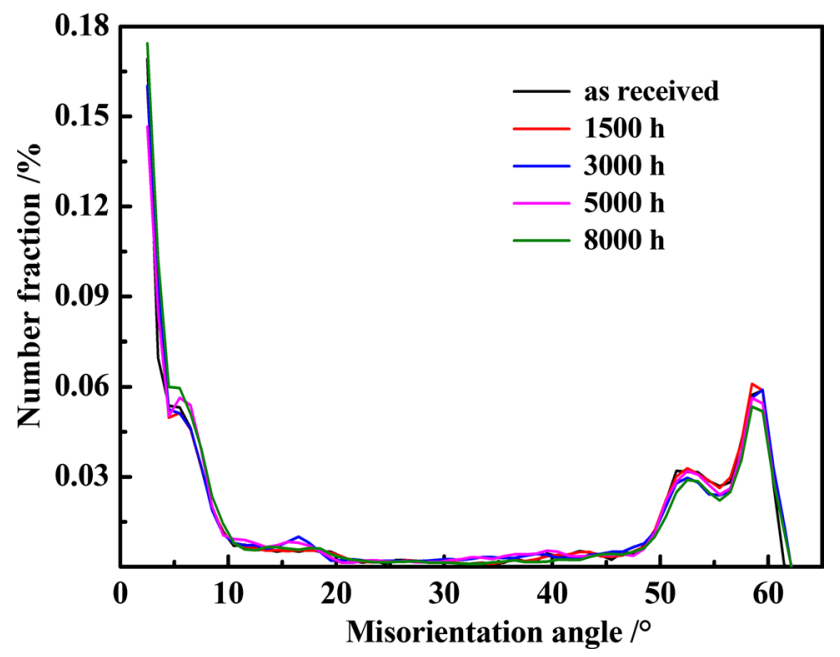

Fig. 4 Misorientation angle distributions in the samples

increase in the LAB proportion indicates that subgrains gradually formed during the thermal aging process, which is consistent with the results in Fig. 3. The reason for the decrease in HABs can be grain coarsening, which reduced the HABs per unit volume.

\subsection{Physical Properties of the Laves Phase Precipitates}

A BSE image of the alloy before and after thermal aging is shown in Fig. 5, where the bright particles are Laves phase precipitates and the gray particles are $M_{23} \mathrm{C}_{6}$ carbide particles. There were hardly any Laves phases observed in the asreceived sample because the tempering temperature $\left(750{ }^{\circ} \mathrm{C}\right)$ was higher than the precipitation temperature of the Laves phases $\left(650^{\circ} \mathrm{C}[4,11-13]\right)$, as shown in Fig. 5a. Some fine Laves phases can be found in the sample that was thermally aged for $1000 \mathrm{~h}$ (Fig. 5b). The number and size of the Laves phases in the sample that was thermally aged for $1500 \mathrm{~h}$ significantly increased (Fig. 5c), indicating that the Laves phases in the thermally aged samples simultaneously grew and precipitated. The Laves phases primarily precipitated at the grain and martensitic lath boundaries.

The physical properties of the Laves phase precipitates, which were calculated from the BSE images, are shown in Fig. 6. Rapid Laves phase precipitation occurred within 

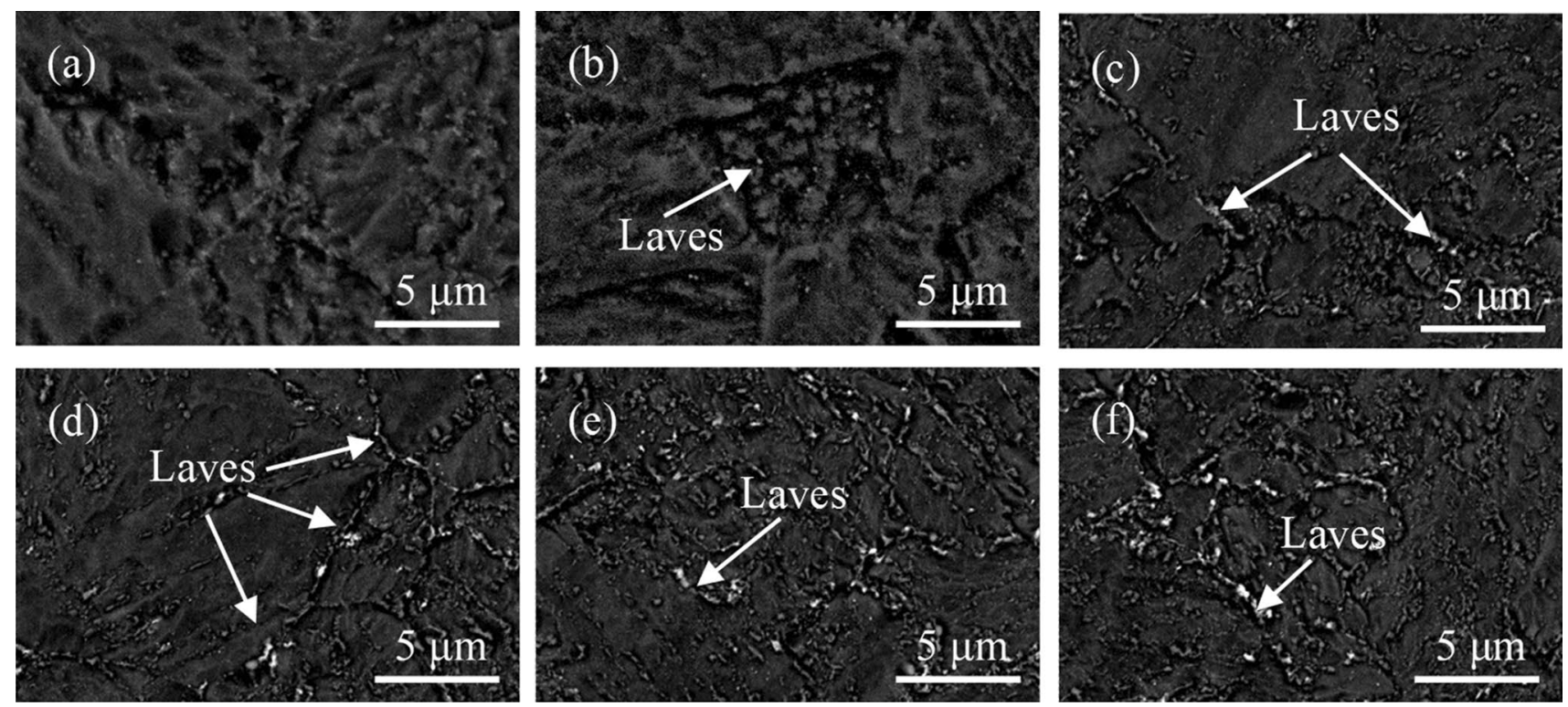

Fig. 5 BSE images of the as-received and aged steels: a as-received, b $1000 \mathrm{~h}, \mathbf{c} 1500 \mathrm{~h}, \mathbf{d} 3000 \mathrm{~h}, \mathbf{e} 5000 \mathrm{~h}$, and f $8000 \mathrm{~h}$

$3000 \mathrm{~h}$, with observed increases in both the density and size of the precipitates, resulting in a rapid increase in volume fraction. The volume fraction of the Laves phase precipitates stabilized after $3000 \mathrm{~h}$ of thermal aging and remained approximately constant with further thermal aging. The density of the Laves phase precipitates began to significantly decrease after $3000 \mathrm{~h}$ of thermal aging, but the size of the Laves phase precipitates continued to increase. This observation is consistent with the Ostwald ripening mechanism, which states that the larger particles grow by drawing materials from the smaller particles [22].

The relationship between the volume fraction of the Laves phase precipitates and thermal aging time can be described by the Johnson-Mehl-Avrami equation [23]:

$f_{\mathrm{V}}(t)=1-\exp \left(-\left(t / t_{0}\right)^{n}\right)$

where $t$ is the time (s), $t_{0}$ is the time constant, and $n$ is a time exponent that is dependent on the type of phase transition, particularly the nucleation and growth mechanisms. The precipitation of the second phase at the grain boundary is defined by $n=1.5$ when the nucleation rate is constant, and $n=0.5$ when the nucleation rate rapidly decreases to zero for the diffusion-controlled phase transition. The nucleation mechanism of the Laves phase precipitates was investigated using $n$, which was calculated from the Johnson-Mehl-Avrami equation, where $n=0.37$ based on the observed physical properties of the Laves phase precipitates (Fig. 7). The Laves phase precipitates primarily precipitated at the grain and martensitic lath boundaries, as shown in Fig. 5, which indicates that $n=0.5-1.5$ [23]. The observed $n$ value $(0.37)$, which is close to 0.5 , indicates that the nucleation rate of the Laves phase precipitates rapidly decreased. The saturation phenomenon of the nucleation position can easily occur because the grain boundary area was limited. However, further nucleation was not possible because of the absence of a suitable nucleation location, which would result in a rapid decay in the nucleation rate. Furthermore, the segregation of $W$ at the grain boundaries would accelerate Laves phase precipitation [24].

\subsection{TEM-EDS Results}

Some precipitates were $M_{23} \mathrm{C}_{6}$ particles (50-120 nm length, 30-80 nm width), which were observed along the grain boundaries in the bright-field image, EDS image (Fig. 8c), and diffraction pattern; these precipitates have frequently been found in other RAFM steels [1-4]. The $M_{23} \mathrm{C}_{6}$ particles were notably coarsened (70-200 nm length, 50-110 nm width) after $8000 \mathrm{~h}$ of thermal aging at $550{ }^{\circ} \mathrm{C}$ (Fig. 8b). Furthermore, W can be found in the $M_{23} \mathrm{C}_{6}$ particles in the thermally aged alloy (Fig. 8d), which would reduce solid-solution strengthening via Wang et al. [14] evaluated the coarsening behavior of $M_{23} \mathrm{C}_{6}$ in CLAM steel during the thermal aging process and obtained $M_{23} \mathrm{C}_{6}$ particle diameters of $100,130,180$, and $175 \mathrm{~nm}$ before and after 2000,4000 , and $10,000 \mathrm{~h}$ of thermal aging at $550{ }^{\circ} \mathrm{C}$ [25]. The volume fraction of the $M_{23} \mathrm{C}_{6}$ carbides in $9 \mathrm{Cr}$ steel was $0.6-1.5 \%$ at $550{ }^{\circ} \mathrm{C}$. The precipitate contribution to the yield strength can be expressed by Orowan strengthening [24]:

$\sigma_{\text {Or owan }}=3.32 G b \sqrt{f_{\mathrm{v}}} / \overline{d_{\mathrm{V}}}$,

where $\sigma_{\text {Or owan }}$ is the Orowan yield stress (MPa), $G$ is the shear modulus (76 GPa), and $b$ is the Burgers vector 

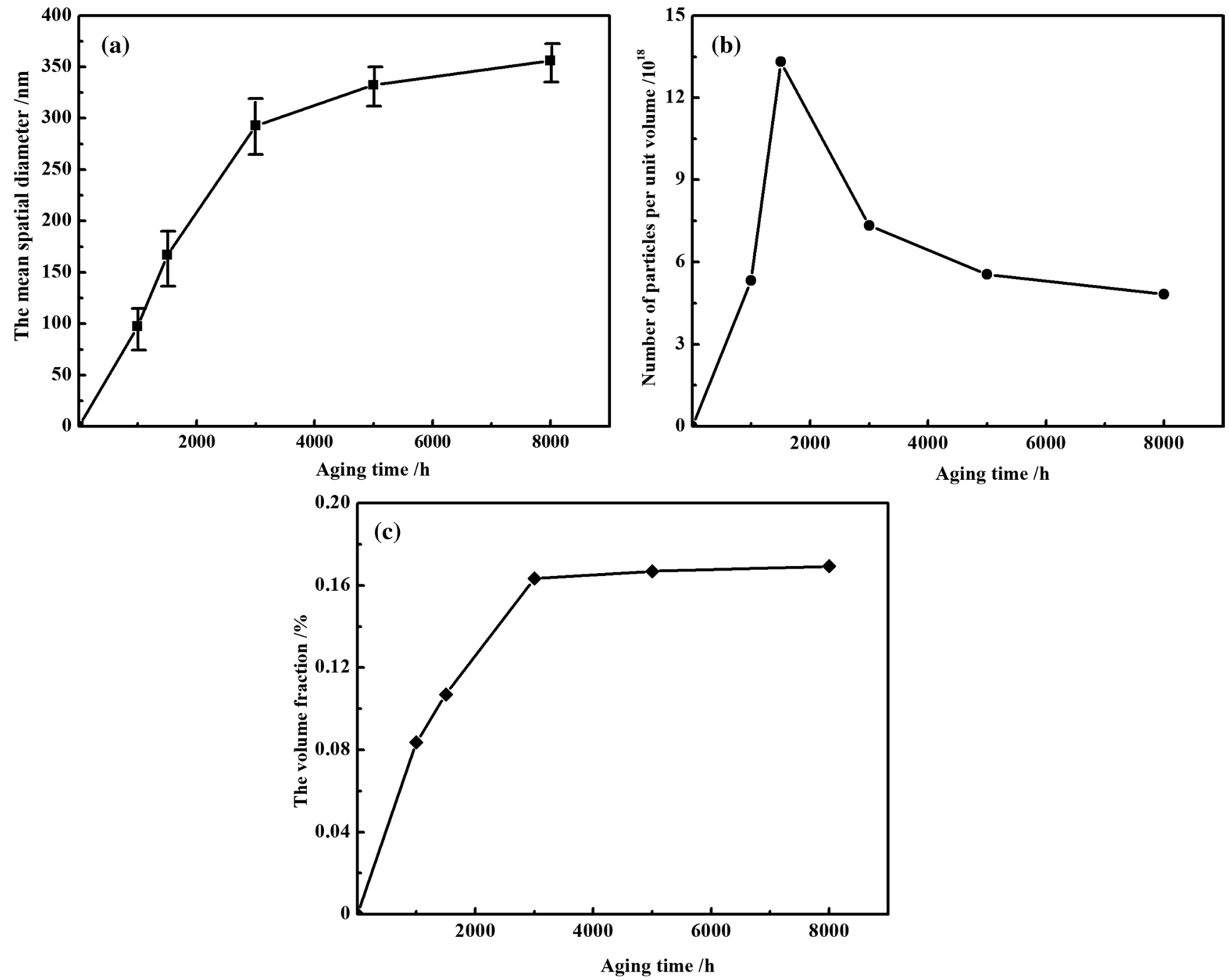

Fig. 6 Physical properties of the Laves phase precipitates in the alloy: a mean spatial diameter, $\mathbf{b}$ number of particles per unit volume, and $\mathbf{c}$ volume fraction

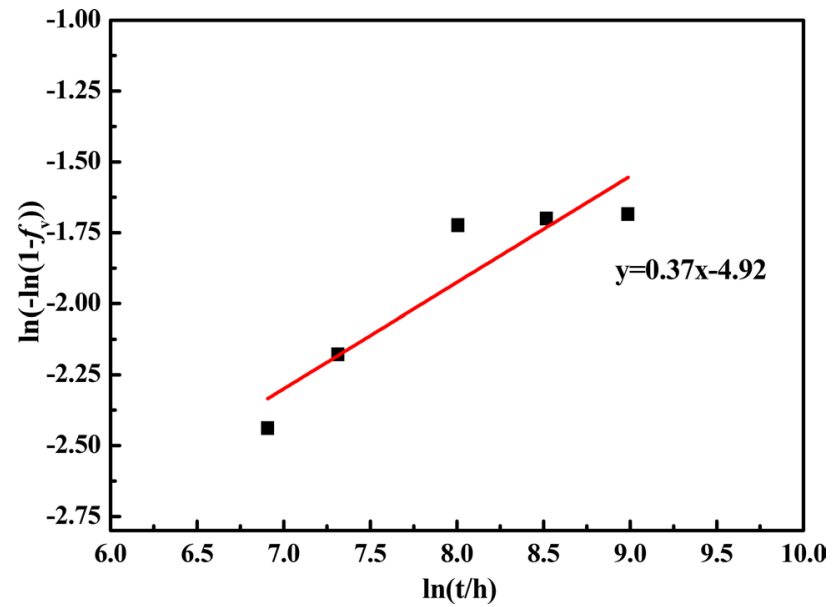

Fig. 7 Evaluation of the time exponent $(n)$ based on the physical properties of the Laves phase precipitates
(0.2487 mm) [3]. The $\sigma_{\text {Or owan }}$ values of the $M_{23} \mathrm{C}_{6}$ carbides with thermal aging time in steel, which are based on Wang's results and the aforementioned Orowan strengthening model, are given in Fig. 9, where the yield stress of the $M_{23} \mathrm{C}_{6}$ carbides gradually decreases during the thermal aging process.

The Laves phase precipitates formed and coarsened during the thermal aging process. They had an elongated shape after $1500 \mathrm{~h}$ of thermal aging, as shown in Fig. 10a. The bright-field and EDS images, and the diffraction pattern indicated that the Laves precipitates (252 nm length, $51 \mathrm{~nm}$ width) were generally much larger than the $M_{23} \mathrm{C}_{6}$ particles and then underwent rapid grain coarsening with continued thermal aging, with large Laves phase precipitates $(365 \mathrm{~nm}$ length, $188 \mathrm{~nm}$ width) observed after $8000 \mathrm{~h}$ of thermal aging, as shown in Fig. 10b. The Orowan stress of the Laves phase precipitates with thermal aging time is shown in Fig. 9, where a rapid decrease occurred between 1000 and 

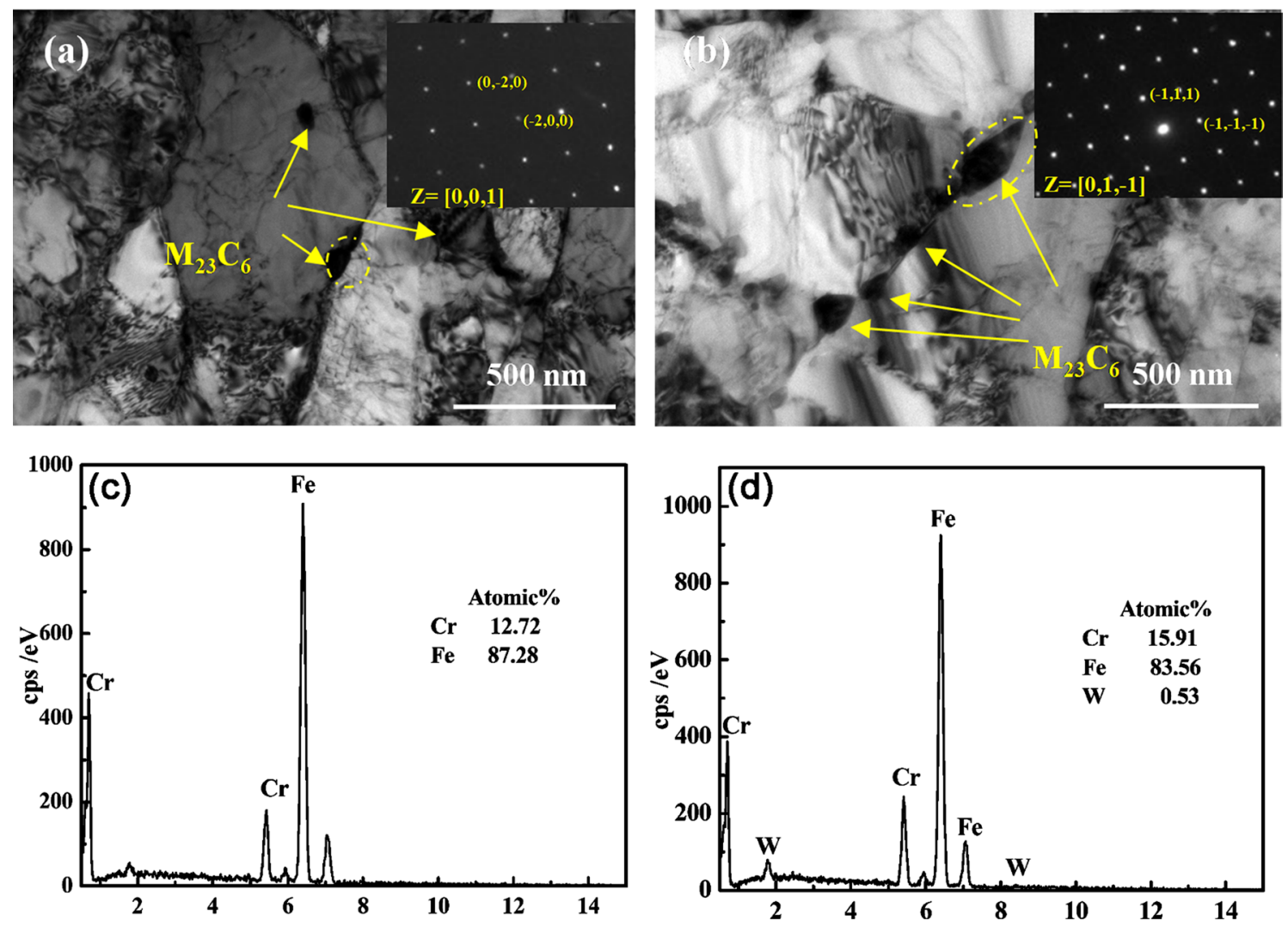

Fig. 8 TEM micrographs (a, b) and EDS results (c and d) of the $M_{23} \mathrm{C}_{6}$ carbides in the as-received alloy (a, c) and sample that was thermally aged for $8000 \mathrm{~h}(\mathbf{b}, \mathbf{d})$

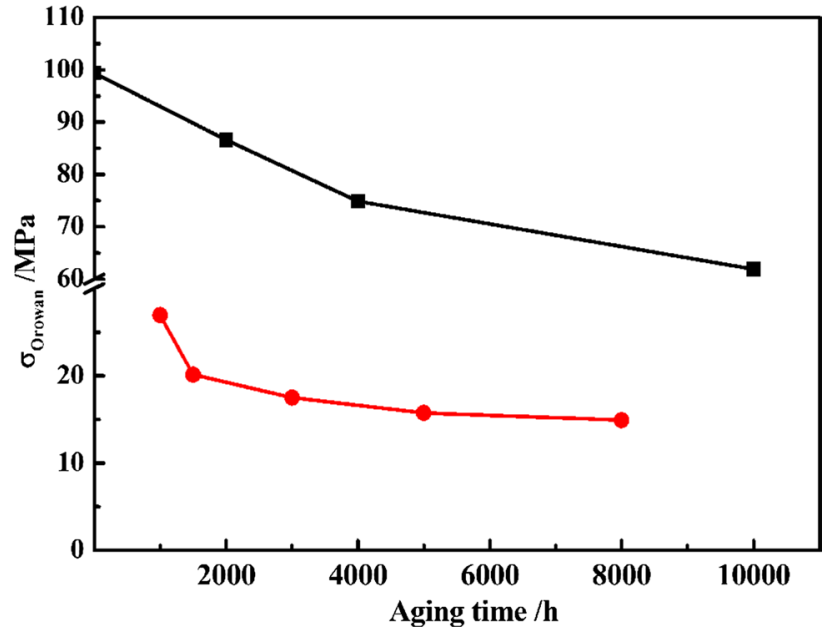

Fig. 9 Orowan yield stresses of the $M_{23} \mathrm{C}_{6}$ carbides (black) and the Laves phase precipitates (red) with thermal aging time

$5000 \mathrm{~h}$, stabilizing at $\sim 15 \mathrm{MPa}$ with further thermal aging. There was good correspondence between the Orowan stress changes and the precipitation and coarsening of the Laves phase precipitates, with the Orowan stresses being much lower than those of the $M_{23} \mathrm{C}_{6}$ carbides.
Figure 11 shows that some small particles precipitated in the alloys. Fine precipitates were present in the as-received alloy, as shown in Fig. 11a, with the EDS results indicating that they primarily comprised $\mathrm{Ta}, \mathrm{Fe}$, and $\mathrm{Cr}$ (Fig. 11e). The bright-field and EDS images, and the diffraction pattern identified the precipitates as $\mathrm{TaC}$ particles that were $10-25 \mathrm{~mm}$ in size. A small degree of growth was observed in these $\mathrm{TaC}$ precipitates after $3000 \mathrm{~h}$ of thermal aging (Fig. 11b). New particles (NPs) formed, which were $\sim 30 \mathrm{~nm}$ in size, after $5000 \mathrm{~h}$ of thermal aging (Fig. 11c), with the EDS results and diffraction pattern (Fig. 11f) identifying these NPs as $\mathrm{V}_{3} \mathrm{Zr}_{3} \mathrm{C}$ (Cubic, Fd-3 mS, $a=b=c=1.212 \mathrm{~nm}$, $\alpha=\beta=\gamma=90^{\circ}$ ). The $M X$ particles coarsened after $8000 \mathrm{~h}$ of thermal aging, with grain sizes in the $15-40 \mathrm{~nm}$ range (Fig. 11d). Furthermore, Ta-rich $M X$ precipitates and $\mathrm{V}_{3} \mathrm{Zr}_{3} \mathrm{C}$ particles were frequently observed along the dislocation planes, which indicated that the dislocation movement would be effectively impeded by these particles.

\subsection{Evolution of Mechanical Properties}

Hardness is an important property that is indicative of the degree of material aging, because a decrease in hardness results in a decrease in the creep properties of heat-resistant 

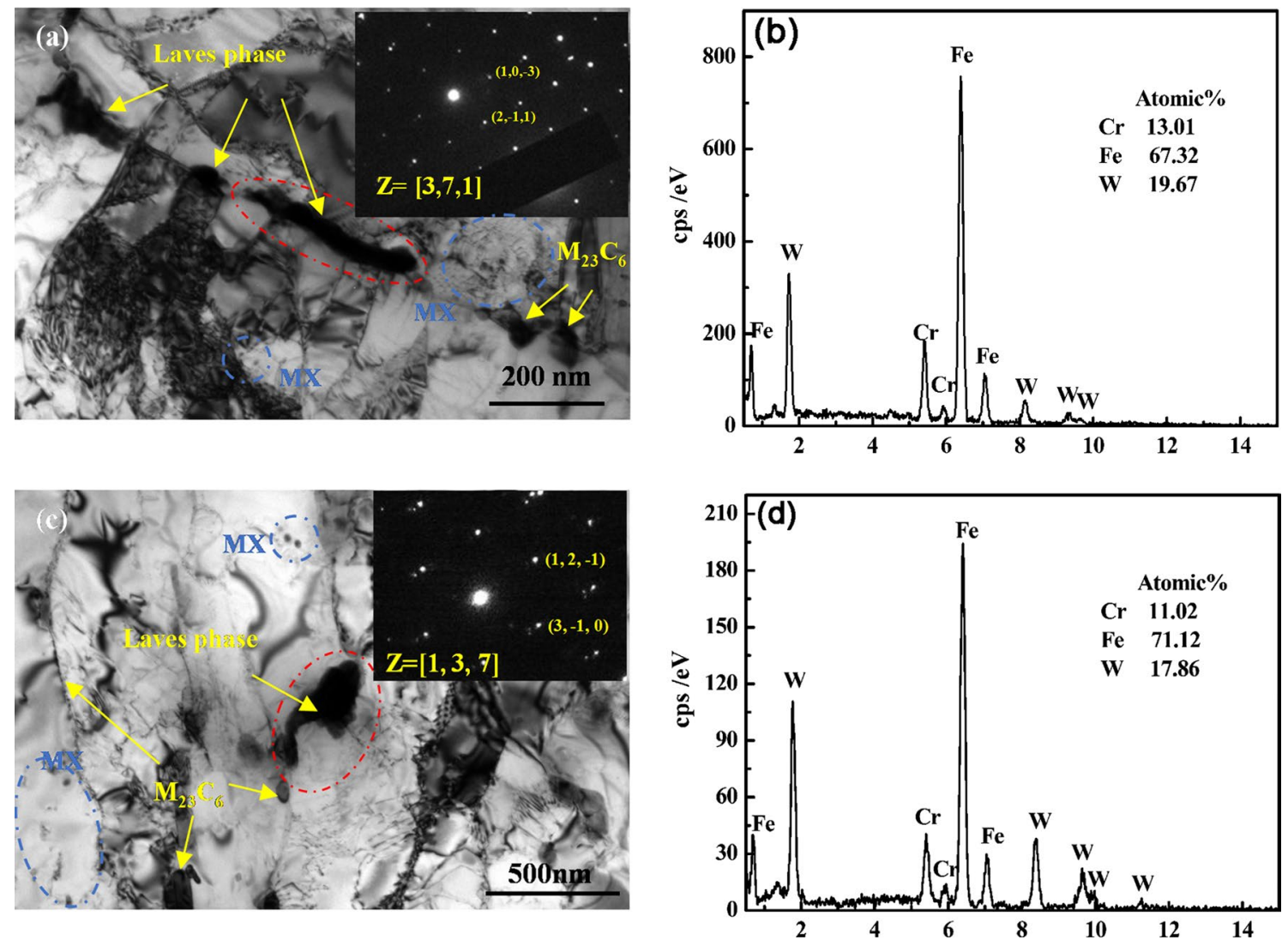

Fig. 10 TEM micrographs (a, b) and EDS results $(\mathbf{c}, \mathbf{d})$ of the samples that were thermally aged for $1500 \mathrm{~h}(\mathbf{a}, \mathbf{b})$ and $8000 \mathrm{~h}(\mathbf{c}, \mathbf{d})$

steel $[26,27]$. The effect of thermal aging time on alloy hardness is demonstrated in Fig. 12, where the hardness first decreased with thermal aging, stabilized at $3000 \mathrm{~h}$, peaked at $5000 \mathrm{~h}$, and then rapidly decreased with further thermal aging. The mean hardness of the as-received sample was $231 \mathrm{HV}$, which decreased to $216 \mathrm{HV}$ after $8000 \mathrm{~h}$ of thermal aging. The hardness peak at $5000 \mathrm{~h}$ was $233 \mathrm{HV}$, which was due to the new $\mathrm{V}$ - and $\mathrm{Zr}$-containing precipitates. The dislocation mobility can be effectively hindered by the $M X$ carbides and the $\mathrm{V}$ - and $\mathrm{Zr}$-containing precipitates, as shown in Fig. 4, which was responsible for the increased hardness. The grain coarsening of carbides resulted in the decreased hardness after $8000 \mathrm{~h}$ of thermal aging.

The effect of thermal aging on alloy strength is shown in Fig. 13. The strength first decreased and then increased, with an inflection point and peak strength at 1500 and $5000 \mathrm{~h}$, respectively. The yield strength $\left(\sigma_{\mathrm{y}}\right)$ of materials during the thermal aging process can be expressed as [28]

$\sigma_{\mathrm{y}}=\sigma_{\mathrm{P}}+\sigma_{\mathrm{S}}+\sigma_{\mathrm{M}}$,

where $\sigma_{\mathrm{P}}$ is the contribution of precipitation strengthening, $\sigma_{\mathrm{S}}$ is the contribution of solution strengthening, and $\sigma_{\mathrm{M}}$ is the contribution of the matrix (e.g., microstructure, grain size). The rapid decrease in $M_{23} \mathrm{C}_{6}$ Orowan stress (Fig. 9), coupled with the grain coarsening (Fig. 2), during the early stages of thermal aging led to the decrease in yield strength $(574 \mathrm{MPa} \rightarrow 546 \mathrm{MPa})$. The subsequent increase in yield strength $(546 \mathrm{MPa} \rightarrow 583 \mathrm{MPa}$ ) was due to the precipitation of the Laves phases and $\mathrm{V}_{3} \mathrm{Zr}_{3} \mathrm{C}$ particles. Both the size and volume fraction of the precipitates in the alloy stabilized after $5000 \mathrm{~h}$ of thermal aging, with the yield strength slightly decreasing ( $583 \mathrm{MPa} \rightarrow 543 \mathrm{MPa}$ ) because of additional grain coarsening after further thermal aging. The elongation fluctuated between $20 \%$ and $24 \%$ during the thermal aging process.

The impact energy of the samples is shown in Fig. 14, with the DBTT obtained by fitting the Boltzmann function to the Charpy impact data [4,11-13]. The grain size and second phase of the precipitates were the primary factors that effectively influenced the observed impact properties [4]. The effect of grain size on alloy toughness is primarily manifested by hindering microcrack growth along the grain boundaries in the materials. Grain refinement can effectively increase the intergranular area per unit volume and then increase the resistance to microcracking. However, not all types of grain boundaries can effectively 

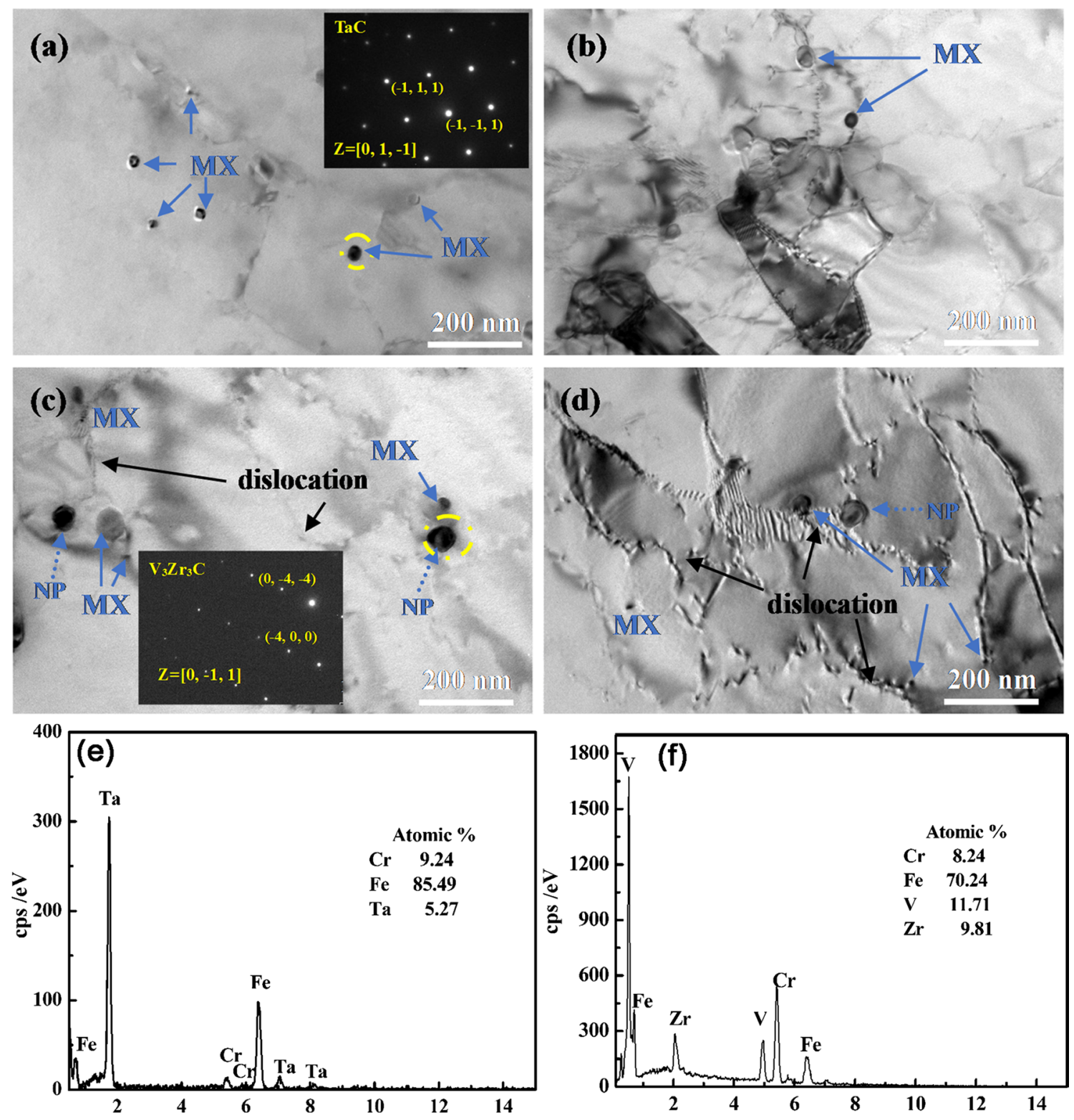

Fig. 11 TEM images (a-d) and EDS results $(\mathbf{e}, \mathbf{f})$ of the $M X$ carbides in the as-received and thermally aged samples: as-received (a, e), $3000 \mathrm{~h}$ (b), $5000 \mathrm{~h}(\mathbf{c}, \mathbf{f})$, and $8000 \mathrm{~h}(\mathbf{d})$

hinder microcrack growth. It has been reported that the effect of HABs, such as austenite grain boundaries, on crack growth was much greater than that of LABs (e.g., subgrain boundaries) [29]. Although some LABs formed during the thermal aging process, they cannot effectively hinder crack growth and improve the impact properties of the alloy. The phase boundary between the second phase and the matrix not only effectively prevented crack propagation but also easily initiated microcracks. The lowtemperature brittleness of the alloy was due to the reduced fracture strength of the alloy relative to its yield strength [30]. Cracks will form and rapidly expand in the material once the stress is greater than the fracture strength, particularly at the grain or phase boundary, such that brittle fracture will occur without plastic deformation. The critical fracture stress $\left(\sigma_{c f}\right)$ can be expressed as follows [30]:

$\sigma_{c f}=\sqrt{\pi E /\left(1-v^{2}\right)} \cdot \sqrt{\gamma / D}$

where $E$ is the Young's modulus, $\nu$ is the Poisson ratio, $\gamma$ is the interfacial energy at the particle-matrix interface $\left(0.4-1.1 \mathrm{~J} / \mathrm{m}^{2}\right.$ [23]) or matrix-matrix interface $\left(1-2.1 \mathrm{~J} / \mathrm{m}^{2}\right.$ [23]), and $D$ is the grain or second phase size. $E$ and $\nu$ were constant for the thermally aged alloys. The critical fracture stress equation can be rewritten as 


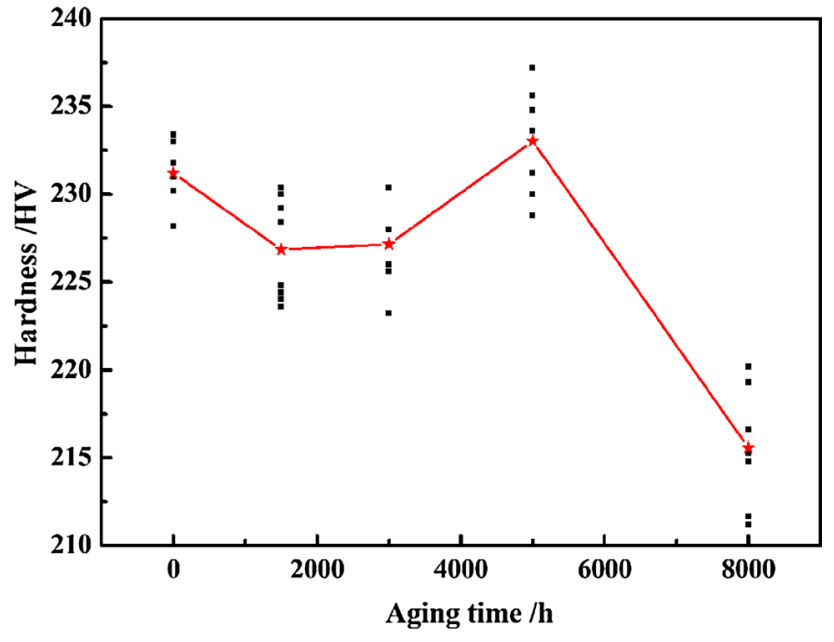

Fig. 12 Effect of thermal aging on alloy hardness

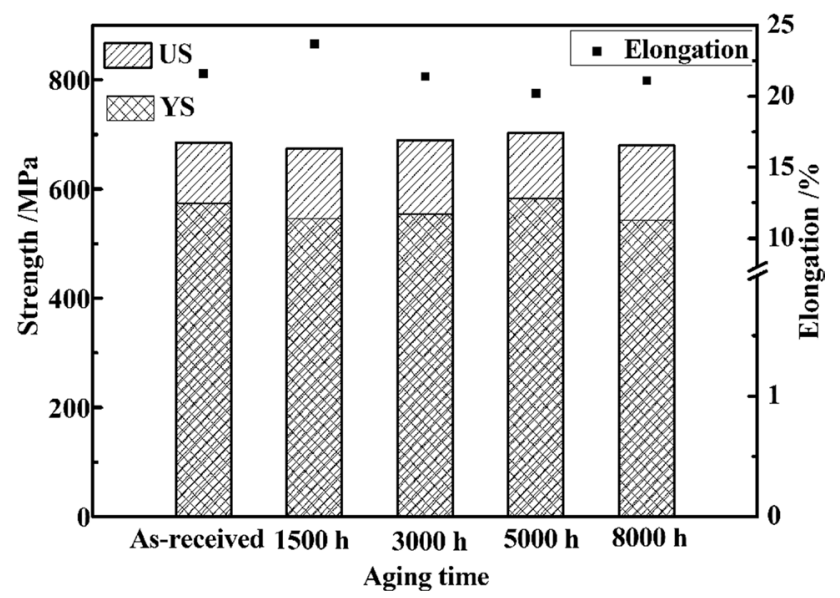

Fig. 13 Effect of thermal aging on alloy strength

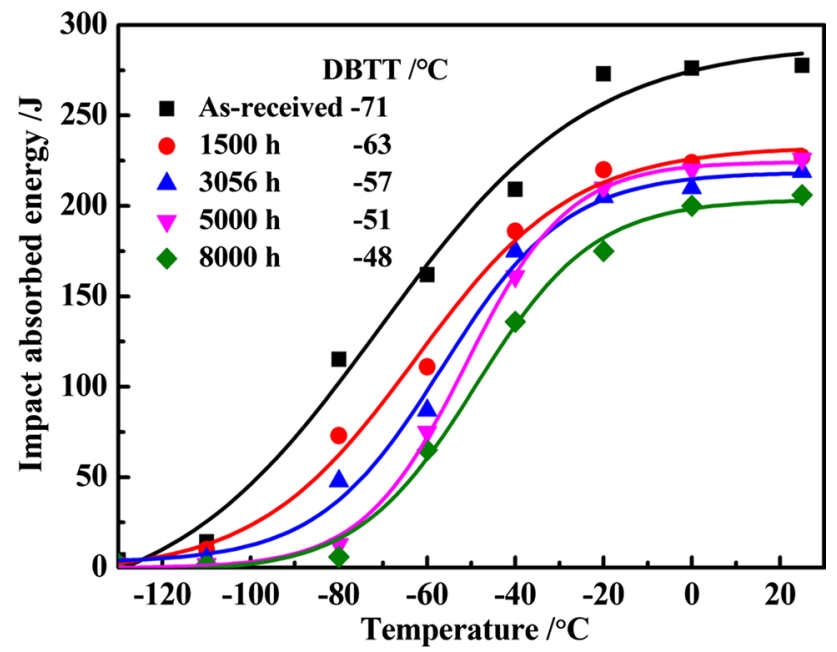

Fig. 14 Impact curves of the as-received and thermally aged samples
$\sigma_{\mathrm{cf}}=A \cdot \sqrt{\gamma / D}$

where

$A=\sqrt{\pi E /\left(1-v^{2}\right)}$,

which is constant for the thermally aged alloys. The size ranges of the second phase and grains in the as-received and thermally aged alloys were 10-355 nm and 11.2-14.2 $\mu \mathrm{m}$, respectively. The critical fracture stress caused by the grain size was $0.27-0.43 A$, and the critical fracture stress caused by the second phase was 1.06-10.49 $A$. Therefore, the change in fracture stress of steel as a function of thermal aging was primarily controlled by the grain size. The toughness of the steel alloy decreased with increasing grain size in the thermally aged alloy, and the DBTT increased from -71 to $-48{ }^{\circ} \mathrm{C}$ during the thermal aging process.

\section{Conclusions}

The thermal stability and mechanical properties of Zr-containing RAFM steel during thermal aging at $550{ }^{\circ} \mathrm{C}$ for up to $8000 \mathrm{~h}$ were studied. The main results are summarized below:

1. The lath martensite morphology of Zr-containing RAFM steel is maintained after thermal aging at $550{ }^{\circ} \mathrm{C}$ for $8000 \mathrm{~h}$. The average grain size of the steel gradually increased with aging and tended to be stable.

2. The $M_{23} \mathrm{C}_{6}$ particles underwent significant grain coarsening after $8000 \mathrm{~h}$ of thermal aging with lengths of 70-200 nm and widths of 50-110 nm observed. There was a slight increase in the size of the $\mathrm{TaC}$ precipitates with thermal aging. Some NPs $\left(\mathrm{V}_{3} \mathrm{Zr}_{3} \mathrm{C}\right), \sim 30 \mathrm{~nm}$ in size, were observed in the sample after $5000 \mathrm{~h}$ of thermal aging, which effectively impeded dislocation movement to improve the mechanical property of the steel.

3. The Laves phase precipitates formed along the grain and martensite lath boundaries after $1000 \mathrm{~h}$ of thermal aging, and grew rapidly. The Laves phase precipitates increased monotonically with thermal aging, and the volume fraction of the Laves phase precipitates in the alloy stabilized at $\sim 0.17 \%$ after $3000 \mathrm{~h}$ of thermal aging. Both the strength and the hardness of the alloy decreased with thermal aging time, although a hardness peak did appear at $5000 \mathrm{~h}$ due to the precipitation of Laves phase particles.

4. The yield strength of the steel decreased from 574 to $543 \mathrm{MPa}$, the tensile strength decreased from 685 to $680 \mathrm{MPa}$, and the DBTT increased from -71 to $-48^{\circ} \mathrm{C}$ after thermal aging for $8000 \mathrm{~h}$ because of the coarsening of grains and the second phases. 
Acknowledgements This work was financially supported by the National Natural Science Foundation of China (Nos. 51874081 and 51574063) and the Fundamental Research Funds for the Central Universities (No. N150204012) and the Liaoning Province Doctoral Research Initiation Fund Guidance Project (No. 20170520079).

\section{References}

[1] S.H. Chen, L.J. Rong, J. Nucl. Mater. 459, 13 (2015)

[2] F. Abe, Sci. Technol. Adv. Mater. 9, 1 (2008)

[3] H.K. Kim, J.W. Lee, J. Moon, C.H. Lee, H.U. Hong, J. Nucl. Mater. 500, 327 (2018)

[4] G.X. Qiu, D.P. Zhan, C.S. Li, M. Qi, Z.H. Jiang, H.S. Zhang, Mater. Sci. Technol. 34, 2018 (2018)

[5] Y.F. Li, Q.Y. Huang, Y.C. Wu, Y.N. Zheng, Y. Zuo, S.Y. Zhu, Fusion. Eng. Des. 82, 2683 (2007)

[6] K.A. Darling, R.N. Chan, P.Z. Wong, J.E. Semones, R.O. Scattergood, C.C. Koch, Scr. Mater. 59, 530 (2008)

[7] H.J. Xu, Z. Lu, D.M. Wang, C.M. Liu, Nucl. Eng. Technol. 49, 178 (2017)

[8] Y.B. Chun, S.H. Kang, D.W. Lee, S. Cho, Y.H. Jeong, A. Zywczak, C.K. Rhee, Fusion Eng. Des. 109-111, 629 (2016)

[9] P. Dou, A. Kimuraa, R. Kasadaa, T. Okudab, M. Inouec, S. Ukaid, S. Ohnukid, T. Fujisawae, F. Abef, J. Nucl. Mater. 444, 441 (2014)

[10] Y.B. Chun, D.W. Lee, S. Cho, C.K. Rhee, Mater. Sci. Eng., A 645, $286(2015)$

[11] G.X. Qiu, D.P. Zhan, C.S. Li, M. Qi, Z.H. Jiang, H.S. Zhang, J. Mater. Eng. Perform. 28, 1067 (2019)

[12] D.P. Zhan, G.X. Qiu, C.S. Li, M. Qi, Z.H. Jiang, H.S. Zhang, J. Iron. Steel Res. Int. (2019). https://doi.org/10.1007/s42243-01900332-9
[13] G.X. Qiu, D.P. Zhan, C.S. Li, M. Qi, Z.H. Jiang, H.S. Zhang, Nucl. Eng. Technol. 51, 1589 (2019)

[14] W. Wang, X.D. Mao, S.J. Liu, G.X.B. Wang, J. Mater. Sci. 53, 4574 (2018)

[15] G. Dimmler, P. Weinert, E. Kozeschnik, H. Cerjaka, Mater. Charact. 51, 341 (2003)

[16] J. Hald, In. J. Pres. Ves. Pip. 85, 30 (2008)

[17] A. Karasev, H. Suito, Metall. Mater. Trans. B 30, 259 (1999)

[18] W. Wang, S.J. Liu, G. Xu, B.R. Zhang, Q.Y. Huang, Nucl. Eng. Technol. 48, 518 (2016)

[19] W. Wang, S.J. Liu, G. Xu, B.R. Zhang, Q.Y. Huang, Fusion Eng. Des. 115, 74 (2017)

[20] Y.F. Li, H. Abe, F. Li, Y. Satoh, Y. Matsukawa, T. Matsunagaa, T. Muroga, J. Nucl. Mater. 455, 568 (2014)

[21] T. Karthikeyan, V. Thomas Paul, S. Saroja, A. Moitra, G. Sasikala, M. Vijayalakshmi, J. Nucl. Mater. 419, 256 (2011)

[22] Q. Lu, W. Xu, V.D.Z. Sybrand, Metall. Mater. Trans. A 45, 6067 (2014)

[23] Q.L. Yong, Secondary Phase in Steels (Metallurgical Industry Press, Beijing, 2006)

[24] X. Wang, Q. Xu, S.M. Yu, L. Hu, H. Liu, Y.Y. Ren, Mater. Chem. Phys. 163, 219 (2015)

[25] A. Gustafsona, M. Hättestrandb, Mater. Sci. Eng. A 333, 279 (2002)

[26] J.M. Pardal, S.M. Tavares, M.P.C. Fonseca, M.R. da Silva, J.M. Neto, H.F.G. Abreu, J. Mater. Sci. 42, 2276 (2007)

[27] M.S. Li, L.F. Wang, X. Xie, L. Qin, X.Q. Zhang, J. Hfut. 27, 518 (2004)

[28] S. Esmaeili, D.J. Lloyd, W.J. Poole, Acta Mater. 51, 2243 (2003)

[29] M.C. Zhao, T.Y. Zeng, J.L. Li, H.X. Fang, Y.C. Zhao, A. Atrensb, Mater. Sci. Eng. A 528, 4217 (2011)

[30] J. Du, M. Strangwood, C. Davis, J. Mater. Sci. Technol. 28, 878 (2012) 